\title{
Planetary IQ Prerequisite for a Shared Vision on Our Planet's Future: Can We Align and Engineer Ourselves out of the Tragedy of Commons?
}

\author{
Ruud Weijermars \\ Alboran Energy Strategy Consultants \\ $\&$ \\ Department of Geotechnology, Delft University of Technology \\ Stevinweg 1, Delft 2628CN, the Netherlands \\ E-mail: R.Weijermars@TUDelft.nl
}

Received: October 12, 2011 Accepted: October 26, $2011 \quad$ Published: December 31, 2011

doi:10.5539/eer.v1n1p147 URL: http://dx.doi.org/10.5539/eer.v1n1p147

\begin{abstract}
Uniting on a common vision for the management of our Planet's future environment remains a formidable challenge. Prophecies and visions warning for an impoverished and overexploited future planet have thus far made little difference for man's choices and decisions on the development of Earth's finite natural resources. Exponential growth of nearly every usage of our natural resources continues unabated, although the unfolding of an environmental tragedy is increasingly well documented and becomes harder to deny. The basic message of past visionaries is reinforced in this essay. Some of us argue that the cost of environmental engineering is simply too high. Others point out that the deferred cost due to irresponsible engineering of our environment will be even higher. The development of a higher Planetary IQ is postulated here as a prerequisite for the adoption of a globally shared vision for our planet's future. The absence of such a shared vision for our planet's future will stand firmly in the way of developing and implementing the various strategic targets (e.g., biodiversity conservation \& GHG emission control) proposed by major institutions to establish a sustainable future for mankind. Game theory and decision-making tools can suggest possible outcomes of multi-stakeholder processes, but in reality the probability of successfully engineering our future remains highly uncertain - if not utopia. The Planetary IQ Society is launched to stimulate the development of shared visions and solutions for a sustainable future.
\end{abstract}

Keywords: Shared vision, Stakeholder alignment, Future life, Organizational learning, Planetary IQ, Sustainable development, Normative scenarios, Natural resource management

\section{Introduction}

"In 'Our Common Future' we asked ourselves two simple questions: how will it be possible to meet the needs of all the world's people? And how can we ensure that future generations are able do the same? ... By striving for consensus and concerted action, we pursue the goals of sustainable development and poverty reduction. There is no purpose more vital, noble, and just." Gro Harlem Brundtland, Earth Summit, Johannesburg, 2002.

Humans are well on their way to create the most dramatic and abrupt changes ever found in the 4,500 million years of Earth history. The current extinction rate of species and the rate of climatic change (Stern Report, 2006; IPCC, 2007) indicate that the anthropogenic impact on our environment is now comparable to or exceeding that of past geological crises. The disappearance rate of our species over the past 40 years is accelerating and exceptionally high when placed in the context of Earth's evolutionary history of life (Lawton, J., and May, R., 1995). We know that the genetic mutation rate of most species is commonly too slow to accommodate current environmental changes (Meffe, G. K., and Carroll, C. R., 1997). Unabated genetic pollution, habitat destruction and degradation due to manmade structures, global warming, overharvesting, overfishing, manmade predator introductions and co-extinction have accelerated the extinction process over the past decade (Butchart, S.H.M. et al., 2010). A recent study by scientists from the International Union for Conservation of Nature (IUCN) indicates that $20 \%$ of the world's remaining vertebrates is threatened with extinction and will be lost in the wild within 
decades without conservation efforts (Hoffman, M. et al., 2010). Overfishing and impact of pollution have pushed a major portion of ocean life to the brink of mass extinction (Alroy, J., 2010).

The geological past has recorded numerous abrupt changes in the biosphere. Present day manmade changes may surpass the impact of natural geological crises (Bryant, P. J., 2005). Nearly all Earth's land surfaces have been cultivated and polluted. Marine sediments show a sudden, enormous enrichment in heavy metals and rare earth elements never seen before. Changes in air composition affect our climate - the impact of mankind's technocratic creations on the earth's ecosystem is unprecedented.

Recent studies emphasize that the result of degrading and destructed ecosystems (B. Ewing, et al., 2010) goes further than accelerating the loss of biodiversity. Such a loss also means a reduction in natural buffers and biogenic processes that regulate the quality of our food resources; examples are: natural purification and replenishment of drinking water, natural pollination of our crops, and natural pest control agents (EC Report, 2008). Evidence is mounting that we have reason to heed the financial consequences of current changes to our environment. The degradation of our ecosystem has been calculated to cost the world's economy around 50 billion Euros per year (EC Report, 2008). This sum is the extra cost we have to incur to replace the loss of natural ecosystem services. By 2050, the opportunity cost for not having preserved biodiversity at year 2000 levels will have lead to an additional cost of 14 trillion Euro, equivalent to 7\% loss in global GDP in 2050 (EC Report, 2008). The principal drivers for an increased anthropogenic pressure on our environment are the global growth in population, economic activity, energy consumption, and food production.

In order to change our destiny, the question remains what vision and associated strategy mankind should follow to manage our future world's life and environment. This essay reviews past visionaries and highlights the importance - and limitations of - global summits (Section 2), evokes the power of science fiction to look into our future (Section 3), highlights the current trend to regulate satisficing behavior that lies at the base of the Tragedy of Commons (Section 4), and introduces Planetary IQ as a prerequisite for developing a shared vision for our planet's environmental future (Section 5). A final deliberation muses whether we can effectively engineer our future environment (Section 6).

\section{Past Visionaries and Recent Global Summits}

Past visionaries have repeatedly pointed out to us that the exponential growth, which seems to characterize many of our human desires and activities, is not sustainable indefinitely. Malthus (Malthus, Th., 1798) was one of the first to make the case: exponential growth of population size would outpace the slow (linear) growth of food production. Malthus conclusions were correct based on his model assumptions, which excluded the impact on food production of innovation and technological advances (Ehrlich P., and Holdren J., 1971). An exponential increase in food provision has been realized due to the industrial revolution and subsequent economies of scale. The planet's food provision capacity has thus managed to keep pace with population growth and defied Malthus' predictions over the past 200 years. Efficiency improvements in agriculture and meat production, global transportation opportunities, and cheap energy sources enabled the global integration of the food supply chain at affordable prices for many - although poverty still persists widely in 2011.

The past demographic explosion has been further supported by the discovery of cheap fossil energy sources (first coal, then oil and finally natural gas), which all have seen consumption growth enabled by exponential growth in production volumes. The possibility of obstacles to this exponential growth first came into broad focus when Hubbert (Hubbert, M. K., 1949) postulated his peak oil theory: oil was finite, and production rates would overtake reserve replacement rates by about year 2000. The reasoning of Hubbert (Hubbert, M. K., 1949) remains sound and solid, but - not unlike the Malthusian population peak theory - was defeated by timely innovations and technological advances that tend to push the fossil energy peak forward in time. The peak oil antagonists have been very vocal in pointing out that fossil energy supply can be prolonged almost indefinitely, due to technological innovation as long as global energy prices support this progress.

In essence, it is our ingenuity that has been able to defeat both Malthus and Hubbert's peak theories, at least until now. As a consequence of our technocratic 'success', exponential growth has also occurred even in the emission of major greenhouse gases (GHGs: carbondioxide, methan, and nitrious oxide). We now live in times of heightened concern and anxiety about global warming due to the rise of GHGs in step with a rise in volume of fossil energy conversion. The burden on our environment due to our success in defying both Malthus and Hubbert became first apparent in Hardin's (Hardin, G., 1968) classic Science paper 'Tragedy of Commons'.

Hardin (Hardin, G., 1968) drew attention to our limited sense of responsibility and uneven rationalizations in burdening our global environment. He explained why progressive pollution of our oceans, atmosphere, outer space and many aquifers and land surfaces is so hard to control. According to Hardin, the utility function of the 
independent rational man says that the cost of the wastes discharged into the commons is less than the cost of purifying wastes before releasing them. Any resource that is not privately owned but shared as 'commons' by groups of people entitles users to take resources from, and put waste, into the commons. The burden on the commons comes from multiple units of waste released by users that acquire benefit from the disposal. The fallacy in this behavior is that the initial removal and subsequent diluted or transformed disposal of the polluted units appears initially as having little impact on the quality of our common resources. The solution seems simple: no space should be left as a 'common' and we must all take responsibility for our 'common' space and protect our interests by preserving its value.

Our critical dependence on access to natural resources for sustainable living was first articulated politically in 1972 by The Club of Rome in 'The Limits to Growth' (Meadows, D. H., et al., 1972). They argued that economic growth could not continue indefinitely because of the limited availability of natural resources. Later, the Brundtland Commission, established by the United Nations in 1983, developed the broad political concept of sustainable development through the course of extensive public hearings. Their report 'Our Common Future' of 1987 (Brundtlandt Committee, 1987) provided the momentum for the 1992 Earth Summit in Rio de Janeiro (Keating, M., 1993), followed by Earth Summits in Kyoto (1997), Cairo (1999), and Johannesburg (2002); a world climate conference was held in Copenhagen (2009). In 2002, world leaders committed, through the Convention on Biological Diversity to achieve by 2010 a significant reduction of the current rate of biodiversity loss; this target has been incorporated into the United Nations Millennium Development Goals (United Nations, Millennium Development Goals Indicators, 2008). Studies presented concurrent with the Nagoya biodiversity summit 2010 have highlighted that the biodiversity conservation target has not been met (Butchart, S.H.M. et al., 2010). Arguably, global summits have encouraged the broad participation of governments, businesses and NGOs to engage in, and improve, sustainable development. In 2012, another ambitious Earth summit will be held in Rio de Janeiro, dedicated to vision sharing, cooperation and transformation focused on sustainable development in a green economy. Preserving future value of our environment, and acknowledging its importance, remain major issues for humanity's future prospects.

\section{Science Fiction and Visions of the Future}

Bright minds, science fiction and traditional science tried to help us in anticipating what our distant future will look like. The principles of limits to growth, as stated by the founding fathers of these principles (Robert Malthus, 1766-1834; King Hubbert, 1903-1989; and Garett Hardin, 1915-2003), met little initial support when they were first published. Thomas More gave us his imaginary island Utopia as a blueprint for a perfect society (More, T, 1516). Sustainability may be equated to an ecological utopia (Geus, M. de, 1996), but we do not know yet whether this provides a realistic blueprint for our future. The Tragedy of Commons recognized by Hardin (Hardin, G., 1968) represents a telling example of non-alignment between stakeholders of the commons. Averting the tragedy requires full alignment between stakeholders, which itself remains a formidable challenge. Can we unite on our preferred destiny?

Consciousness of options for our destiny, at a scientific level, improves with evolution of man as a species and with the age of individuals. Being conscious is an observation, deduction and decision-making process. A satirical vision of our future portrays a planet filled with 'virtual reality' creatures that may succeed Earth's traditional biodiversity. A parody essay on future life forms illustrated with cartoons drawn by Gerard 't Hooft (Weijermars, R., 1986), was published long before he won a 1999 Nobel Prize for research in theoretical physics. The essay satirically stated that we may still be optimistic about the future maintenance of pluriform life even after we ruined our environment. The newly started geological era was termed the Polluticum, which is the first stage of the Quinternary that supercedes the Alluvium stage of the Quaternary. Characteristics of this stage are an explosive expansion of the human population, pollution of the hydrosphere and atmosphere, and the extinction of many species of flora and fauna. However, owing to the high level of radioactivity, rapid mutation takes place among the surviving species.

The Jules Verne-like drawings of Figures 1a-d show what successful life forms evolution may result in. For example, a bird species, Torreya Canyoni, has evolved in such a way that its feet resemble skis, so that it is able to land on oil-polluted water surfaces (Figure 1a). Ink-fish-like creatures have developed a propulsion mechanism so strong that they can escape the polluted ocean waters (Figure 1b). Incidentally, they discover enough fuel in the polluted waters to escape our atmosphere and fly to the moon. On the Moon, Sepia explosiva will meet Antennapes charliebrown (Figure 1c), a separate species which has evolved from the ancestors of the flying squid. A motley population of highly technocratic animals will live on Earth at the height of the Polluticum: beware of the aggressive insect Bacchus deliriosus (or wine thief; Figure 1d), which specializes in screwing corks and subsequently emptying the bottle's contents. 
Alternative visions for our Earth's future population and destiny of biodiversity such as seen in societies created in cyberspace and previously in science-fiction may all be possible. Science fiction tends to break out of the traditional bounds of science by creating alternative future worlds and visualizing novel solutions even before we have tools and theories to verify these visions. In a way, the power of science, scenario writing and trend assessments as a collection of observations, theoretical rules, and practical knowledge, documented and developed by humans in a verified fashion, should not be overstated. Surely, the results can be reproduced, verified and understood by us. But more fundamentally, science is the proliferation and excellence of common sense as perceived by the human brain. Science tends to expand into many specialist topics and ideas, often mastered and appreciated in detail only by a distinguished and select group of individuals. Such science tends to focus on solutions to engineer the future we want. Science fiction has helped us to explore futures we dread and might want to avoid.

Luis Buñuel, absurdist Spanish filmmaker of the 20th Century (1900-1983), nicely formulated his wish to see the future (in My Last Breath (Bunuel, L., 1983), p. 256): “As I drift toward my last sigh I often think of a final joke....But will I have the strength to joke at that moment? Only one regret. I hate to leave while there's so much going on. It's like quitting in the middle of a serial. I doubt there was so much curiosity about the world after death in the past, since in those days the world didn't change quite so rapidly or so much. Frankly, despite my horror of the press, I'd love to rise from the grave every ten years or so and go buy a few newspapers. Ghostly pale, sliding silently along the walls, my papers under my arm, I'd return to the cemetery and read about all the disasters in the world before falling back to sleep, safe and secure in my tomb."

The question, of course, remains whether our destiny is a fixed reality where comes-what-comes as nature sees fit to make up for us, or an ideal, malleable place proactively engineered and largely created by ourselves. Can we pre-empt nature's course by perfectly engineering our environment? Or will natural processes prevail and continue to overprint our anthropogenic actions in the long run in a direction that we may not find comfortable? Are we fair in assuming we can master the Earth in a controlled way where we engineer the future environment at convenience and convenient for us?

Is there perhaps any reason, in spite of all our research efforts and global summits, to believe that we will never be able to unite and settle on a common vision for engineering our planet's future? Unlike the smooth communication on Spaceship Enterprise, with its amalgamation of diverse cultures and races, on present-day Earth we still have to bridge many communication barriers across tribes, cultures, and religious groups. Some new medical insights have begun to reveal in which part of the brain our personal decision-making is happening (Fischette, C., 2004). But a lot still needs to be discovered about our own position in the architecture of the universe and nature of things. We still need to solve our differences to make better use of our common knowledge base.

\section{Regulating Satisficing Behavior and Stakeholder Alignment}

Given our inability to see very far into the future or deal with very many things at once, it is in our human nature to set minimal levels of payoff in each area of concern, and then troubleshoot only thereafter where crises arise. In most cases, systems to manage the commons arise after resources are threatened by overuse. This satisficing strategy (March, J. G. and Simon, H. A., 1958) is common, because of the inherent cognitive limits of our human capacity for processing information. While our database of the threats to our 'commons' has significantly improved in recent times (Stern Report, 2006; IPCC, 2007; Wackernagel, M. et al., 2002; the ecological wealth of nations, 2010), the use of these data and the subsequent actions need to be optimized as outcomes of a multi-stakeholder negotiation process.

It is only when the availability of our resources is threatened that the need for regulation becomes apparent to most of us and is supported by the general public's opinion. The proper valuing of our environmental resources as public goods must become subject to an incentive system where individuals share the cost of using, maintaining, and preserving or replacing the resource in question. Unless we really manage to abandon the satisficing principle (i.e., not just aggressively getting the highest instant profit out of our planetary resources without much serious restraint and concern about the longer term effects), there seems little reason to be optimistic about the quality of our future commons.

In a posthumous acknowledgement to the essence of Hardin's Tragedy of Commons, recent normative scenarios suggest that the beneficiary of adverse impacts on natural ecosystems should pay (EC Report, 2010). Reversely, organizations that have a net positive impact may receive monetary benefits from this departure from past satisficing behaviour (REDD Realities, 2009). This vision includes the rescinding of past subsidies on pollutive methods (such as shale gas extraction in the US) and the realignment of incentive structures and fiscal reforms, 
in which the value of natural ecosystems is properly protected, degradations remediated and reversal of negative impacts stimulated. The current trend is to provide policymakers with normative scenarios that quantify the cost of not curbing GHG emissions (OECD/IEA, 2010) and the cost of loss of biodiversity and ecosystems (EC Report, 2008; TEEB, 2010). The strategy advocated by these scenarios is focusing on regulations and policy-making to steer our satisficing behaviour away from adverse impacts. Alternative remedies for moderating emissions from fossil energy consumption are postulated by MacKay (MacKay, D. J. C., 2010); and further modelled in DECC (DECC, 2010).

The TEEB (TEEB, 2010) study includes 10 smart commandments that aim at improved accountability for human impact on our ecosystem and puts a value at biodiversity. Command 1 asks to assess and communicate the role of biodiversity and ecosystem services in the economy and ensure public disclosure of, and accountability for, impacts on nature. Command 2 asks for an upgrade of current natural accounting systems to include the cost and benefits of changes in natural capital stock and eco services and flows. Further commands ask businesses to do the same and account for their impact on nature. In fact, what we see emerging is a vision where principles are 'no net loss' and 'net positive impact' on the quality and value of natural ecosystems as normal business practice, using 'robust biodiversity performance benchmarks'.

Ultimately, the decision-making process of each stakeholder determines whether or not they will align, adopt and support any of the scenarios for our future elaborated for national and international constituencies such as the UK Department of Energy and Climate Change, International Energy Agency, WorldBank and TEEB. The principal 'actors' or stakeholder groups in our society responsible for achieving results in choices about future sustainable development are identified in a recent IAC Report (IAC Report, 2007) as follows:

- Multinational organizations: IEA, UN, Worldbank, regional developments banks, etc.

- Governments: national, regional, local, etc.

- Science and Technology community: academia etc.

- Private Sector: businesses, industry, foundations etc.

- NGOs: world energy council, Earth watch, etc.

- Media: Scholarly journals and Popular media (print, web, radio, TV)

- General Public: social networks, etc.

Each actor considers strategy options, choices and plans. Not all actors will be prepared to share their competitive energy vision and strategy plan. Gro Harlem Brundtland (Gro Harlem Brundtland., 1996) definitely saw a need for top-down design of a vision on our use for natural resources: "The market is effective in directing resources, but less effective in promoting equity, equal opportunity and environmental requirements. These are needs defined by the people, and their political representatives."

Previous research on natural resource management has demonstrated that the perception of increased risk for the long-term resource exploitation will enhance the possibility of cooperation between actors (Ostrom, E., 1990). There is a distinct role for social pressure and norm fairness, which has been elaborated into a dynamic game strategy by Elster (Elster, J., 1989) and Poundstone (Poundstone, W., 1993). Rasmussen and Meinzen-Dick (Rasmussen, L. N. and Meinzen-Dick, R., 1995) have summarized the drivers for multi-stakeholder cooperation as follows: relative benefit, size of usergroup, time horizon, communications, expectations, trust, incentives, stability, social norms, and visibility. Runge (Runge, C. F., 1984) and Ridley (Ridley, M., 1998) have discussed the problems of collective action and the resistance encountered in sharing resources for communal benefit.

Other models have been put forward to help policy-makers in decision-making: one can distinguish models that address organizational behavior [i.e., rational actor model (Allison, G. and Zelikov, P., 1999), macroscopic economic models where the degree of government regulation (Allison, G. and Zelikov, P., 1936) and private enterprising (Friedman, M., 1962)] determined more or less by laws and intervention - and negotiation-oriented utility function models that quantify rational choices based on uncertainty and optimization of cost-benefit ratios (Morgenstern, O. and Von Neumann, J., 1947; Nash, J., 1950, 1951; Axelrod, R., 1997; Myerson, R. B., 1997).

As each of the actor groups formulate their own vision for our future, from their specific vantage point, and for their specific constituency, a very broad range of strategy plans is developed for our future; more than often, the vision behind these strategies remains vague and poorly articulated. The media and general public are generally following the findings and choices of the first five actors. All actors will clearly benefit from an improvement of our common understanding of the dynamics in vision development for our sustainable future. Leadership is increasingly important in the development of a shared vision and for the strategies required to realize that vision. 
Developing a shared vision for the future is not necessarily in competition with religion or theological viewpoints (Figure 2). Some religious interpretations may claim developing a shared vision is not up to us, but remains a divine privilege. A supernatural power, God or nature's origin, has given us our planet, and thus provided us with a home for our ancestors and ourselves. If we not believe in an apocalypse or a divine right to determine our future, then it is up to us to make the right decisions for making the best and the most out of it, for ourselves and for future generations. A life in heaven should not necessarily be more important than life on Earth.

\section{Planetary IQ Prerequisite}

A Planetary IQ framework advocated in detail elsewhere (Weijermars, R., 2011) may further help us to improve rationality in decisions and abandon our past behavior of exploiting nature without impunity and dubious morality. We will make better choices for the future when we succeed in optimizing our ingenuity (Elgin, D., 1993; Ehrlich, P., 2000) by building higher organizational intelligence. Further growth of such localized intelligence may contribute to build a higher Planetary IQ in our society (Figure 3). Planetary IQ is defined (Weijermars, R., 2011) as the globally aggregated outcome of our organizational learning processes; it is the arithmetic average of a representative population of Organizational IQs at anyone time. The improvement of our societal IQ system also involves confrontation of under-educated and faulty risk perceptions held by the general public. Sustainability ethics (Cairns, J. Jr., 2005) must be taken seriously by a majority of us. If we manage to optimize our Planetary IQ, we can make better decisions on issues of global importance.

The concurrent state of our Planetary IQ determines at anyone time our own impact on what future place our descendants will live in. Unfortunately, our Planetary IQ is not functioning at optimum to agree on solutions for our future. Detoriation of our IQ may occur (Weijermars, R., 2011) and some of the principal causes are listed here:

- Geopolitical: Geopolitical tension and war lead to the enhancement of certain business operations, but mostly cause massive collapse in war torn areas as local business failure spreads, communication is impeded, and knowledge is lost.

- Strategic: Strategic embargo's lead to deprival of state-of-the-art knowledge and technology in the embargo countries. Innovation is partly encouraged, but mostly as an inferior solution constrained by the lack of access to substrate ingredients, technology and knowledge.

- Natural hazards: Geo hazards like earthquakes, tsunamis, volcanic explosions, meteoritic impacts, landslides, floods; Epidemics and pests also lead to instant disruption of the regional framework for effective communication between people and businesses. Natural hazards enhance the risk for loss of knowledge repositories.

- Sustainability problems: Overpopulation, depletion of natural resources, and pollution of our environment triggers innovative solutions, but may reach or overrun the limits of our planetary resources and natural recovery systems.

- Corporate governance: Corruption of good governance in nations, regions and organizations is lethal to the development of Organizational Intelligence. Violations and fraud in corporate governance commonly result in catastrophic decline of Corporate IQ and, if persisting or prevailing on the scale of regions and nations, will contribute to the temporal decline of our Planetary IQ.

- Extremism: Terrorism, fanatic nationalism, and religious fundamentalism all have organizational networks characterized by extreme manifestation of groupthink (Jannis, I., 1982). Their actions are disruptive to our Planetary IQ growth, as knowledge flow is shrouded in secrecy and the rule of law is violated on the basis of ideologies that have abandoned some - or all - forms of open communication.

- Education \& vision sharing: Alignment of stakeholders on a common vision \& strategy is not a given. Education is needed to develop our knowledge base. Likewise, vision sharing events are needed to develop a globally supported vision.

A common vision, which requires the exchange of short-term cost for long-term environmental gains, may not find much popular support. As long as political decisions are steered by popular votes in favour of short-term gain, we are unlikely to reach consensus on a common vision for our planet's future. Consequently, the anthropogenic engineering of our future environment will likely continue to be lead by satisficing behaviour. In such a sub-optimum way of engineering our environment, without a common vision, we must concede that the Earth's natural processes may have a better chance to set the master plan for our future. Our home planet may thus continue to dictate and determine our future for us - in spite of our anthropogenic efforts. 


\section{Conclusions}

It may take all of us well into the first half of the $3^{\text {rd }}$ Millennium before we have overcome the major setbacks among others geopolitical tension, sustainability problems, and extremism - that threaten to corrupt our Planetary IQ. Unless we will be able to overcome these mentioned recurrent impediments to growth of our Planetary IQ, we cannot succeed in reaching global alignment on a common vision for our future. A global initiative has been launched under the umbrella of the Planetary IQ Society (Planetary IQ Society, 2011), which aims to stimulate the development of globally shared visions and solutions for a sustainable future.

A major question that still needs to be answered by us, but which can never be proven with certainty for any future date, is whether a prevailing vision for our future may safely assume that we can indeed successfully and comprehensively engineer our planet's complex physical processes, crops and fauna. A strategy to invest in GHG mitigation may be futile if engineering the planet's future by man turns out to be a task too great for us to handle. In the light of the current strain in the global economy, most limits to growth are real.

If proactive engineering of the planet's future is no viable option, a massive shift to engineering solutions that protect us against any adverse impacts of unstoppable and destructive environmental changes may be more realistic. This would comprise localized rather than global climate control, localized dike projects to keep the rising sea-levels at bay rather then trying to fix the global climate. Meanwhile, large-scale destruction of our natural environment means nature's past credit as a natural endowment has been used up and the cost of engineering solutions is definitely leveraged to future generations.

\section{References}

Allison, G. \& Zelikov, P. (1999). Essence of Decision (Explaining the Cuban Missile Crisis). Addison-Wesley.

Alroy, J. (2010). The shifting balance of diversity among major marine animal groups. Science, 329, 1191-1194. http://dx.doi.org/10.1126/science.1189910

Axelrod, R. (1997). The Complexity of Cooperation. Princeton, New Jersey: Princeton University Press.

Brundtlandt Committee. (1987). Our Common Future. Oxford: Oxford University Press.

Bryant, P. J. (2005). Biodiversity and conservation: a hypertext book. School of Biological Sciences of the University of California, Irvine, Ca., USA. [Online] Available: http://darwin.bio.uci.edu/ sustain/bio65/Titlpage.htm

Bunuel, L. (1983). My last breath.

Butchart, S. H. M., et al. (2010). Global Biodiversity: Indicators of Recent Declines, Science, 328, 1164-1168. http://dx.doi.org/10.1126/science.1187512

Cairns, J. Jr. (2005). Ecological overshoot and sustainability ethics. Ethics in Science and environmental Politics, June, 21-22.

DECC. (2010). 2050 Pathway Analysis. Department of Energy and Climate Change. Introduces DECC Energy Scenario 2050 Pathways Calculator Tool. [Online] Available: http://2050-calculator-tool.decc.gov.uk/

EC Report. (2008). The Cost of Policy Inaction (COPI): The case of not meeting the 2010 biodiversity target. [Online] Available: http://ec.europa.eu/environment/nature/biodiversity/economics/pdf/copi.zip

Ehrlich P. and Holdren J. (1971). Impact of Population Growth: complacency concerning this component of man's predicament is unjustified and counterproductive. Science, 171, 1211-1217.

Ehrlich, P. (2000). Human Nature: Genes, Culture and Human Prospect. Washington DC: Island Press.

Elgin, D. (1993). Awakening Earth: Exploring the Evolution of Human Culture \& Consciousness. New York: William Morrow.

Elster, J. (1989). The Cement of Society. A Study of Social Order. Cambridge: Cambridge University Press. http://dx.doi.org/10.1017/CBO9780511624995

Fischette, C. (2004). Psychopathy and Responsibility. Virginia Law Review, 90, 5, 1423-1485. http://dx.doi.org/1 $0.2307 / 3202382$

Friedman, M. (1962). Capitalism and Freedom. Chicago: University of Chicago Press.

Geus, M. De. (1996). Ecologische utopieën - Ecotopia's en het milieudebat. Uitgeverij Jan van Arkel.

Global Footprint Network. (2010). Calculation Methodology for the National Footprint Accounts, (B. Ewing, A. Reed, A., Galli, J. and M. Wackernage. (2010). [Online] Available: http://www.footprintnetwork.org/images/up loads/National_Footprint_Accounts_Method_Paper_2010.pdf 
Gro Harlem Brundtland. (1996). in "Destination Norway - Commerce \& Culture".

Hardin, G. (1968). The Tragedy of Commons. Science, 162, 1243-1248. http://dx.doi.org/10.1126/science.162.3 859.1243

Hoffman, M. et al. (2010). The Impact of Conservation on the Status of World's Vertebrates. Science, Hubbert, M. K. (1949). Energy from Fossil Fuels. Science, 109, 103-109.

IAC Report (2007). Ligthing the way: Toward a Sustainable Energy Future. InterAcademy Council, 174 pages. [Online] Available: http://www.interacademycouncil.net/

IPCC. (2007). Fourth Assessment Report Climate Change, 2007; Released in four distinct sections: (1) Working Group I Report (WGI): Climate Change 2007: The Physical Science Basis.; (2) Working Group II Report (WGII): Climate Change 2007: Impacts, Adaptation and Vulnerability; (3) Working Group III Report (WGIII): Climate Change 2007: Mitigation of Climate Change; (4) The Synthesis Report (SYR).

Jannis, I. (1982). Groupthink. Houghton Miflin Company.

Keating, M. (1993). Agenda for Change: A Plain Language Version of Agenda 21 and Other Rio Agreements. Centre for Our Common Future, Geneva, Switzerland.

Keynes, J. M. (1936). The General Theory of Employment, Interest and Money, Macmillan Cambridge University Press, Royal Economic Society.

Lawton, J., and May, R. (1995). Extinction rates. (eds.). Oxford University Press.

MacKay, D. J. C. (2010). Sustainable Energy - without the hot air. 364 pages. [Online] Available: http://www.withouthotair.com/

Malthus, Th. (1798). An Essay on the Principle of Population. London, printed for J. Johnson in St. Paul's Church-Yard.

March, J. G. and Simon, H. A. (1958). Organizations. (The Satisficing Principle) New York: Wiley.

Meadows, D. H., Meadows, D. L., Randers, J. and Behrens III, W.W. (1972). The Limits to Growth. Universe Books, New York.

Meffe, G. K., and Carroll, C. R. (1997). Principles of Conservation Biology. (eds.). Sunderland, Massachusetts: Sinauer Associates.

More, T. (1516). De optimo rei publicae statu deque nova insula Utopia. [Online] Available: http://www.luminarium.org/renlit/morebib.htm

Morgenstern, O. \& Von Neumann, J. (1947). The Theory of Games and Economic Behavior. Princeton: University Press.

Myerson, R. B. (1997). Game Theory: Analysis of Conflict. Harvard: Harvard University Press.

Nash, J. (1950). Equilibrium points in n-person games. Proceedings of the National Academy of Sciences, 36(1), 48-49. http://dx.doi.org/10.1073/pnas.36.1.48

Nash, J. (1951). Non-Cooperative Games. The Annals of Mathematics, 54(2), 286-295. http://dx.doi.org/10.2307 $/ 1969529$

OECD/IEA. (2010). Energy Technology Perspectives. IEA Publications, Paris, 706 pages.

Ostrom, E. (1990). Governing the Commons. The evolution of Institutions for Collective Action. Cambridge: Cambridge University Press.

Planetary IQ Society. (2011). A new global initiative for developing shared visions and solutions for a sustainable future. [Online] Available: http://www.PlanetaryIQSociety.org

Poundstone, W. (1993). Prisoner's Dilemma. New York: Anchor Books.

Rasmussen, L. N. and Meinzen-Dick, R. (1995). Local Organizations for Natural resource Management. International Food Policy Research Institute, EPTD Discussion Paper No. 11, Washington DC.

REDD Realities. (2009). How strategies to reduce emissions from deforestation and forest degradation could impact on biodiversity and Indigenous Peoples in developing countries, by the Global Forest Coalition, December. [Online] Available: http://www.globalforestcoalition.org/img/userpics/File/publications/REDD-Reali ties.pdf 
Ridley, M. (1998). The Origins of Virtue: Human Instincts and the Evolution of Cooperation. New York: Viking.

Runge, C. F. (1984). Institutions and the free rider: The assurance problem in collective action. Journal of Politics, 46, 154-181. http://dx.doi.org/10.2307/2130438

Stern Report. (2006). Stern Review on the economics of climate change. HM Treasury UK.

TEEB. (2010). The Economics of Ecosystems and Biodiversity: Mainstreaming the Economics of Nature: A synthesis of the approach, conclusions and recommendations of TEEB. [Online] Available: http://www.teebweb.org/LinkClick.aspx?fileticket=bYhDohL_TuM\%3d\&tabid=924\&mid=1813

The ecological wealth of nations. (2010). Earth's biocapacity as a new framework for international cooperation. Global Footprint Network, 38 pages. [Online] Available: http://www.footprintnetwork.org/images/uploads/Ecol ogical_Wealth_of_Nations.pdf

United Nations. (2008). Millennium Development Goals Indicators. UN 2008. [Online] Available: http://unstats.un.org/unsd/mdg/Host.aspx? Content=Indicators/OfficialList.htm, 2008

Wackernagel, M., et al. (2002). Tracking the Ecological Overshoot of the Human Economy. Proc Nat Acad Science, 99(14), 9266-9271. [Online] Available: http://www.pnas.org/content/99/14/9266.full

Weijermars, R. (1986). Evolution on Earth may tell us what ETI look like. Geology Today, 2 (3), 89-91. http://dx.doi.org/10.1111/j.1365-2451.1986.tb01035.x

Weijermars, R. (2011). Building Corporate IQ: Moving the Energy Business from Smart to Genius: Executive Guide to preventing Costly Crises. Springer, London.

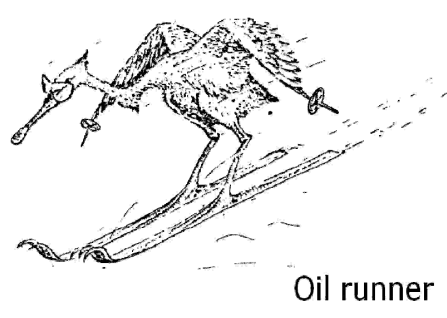

(Torreya canyoni)

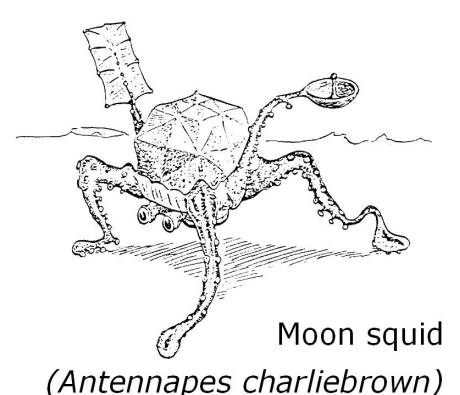

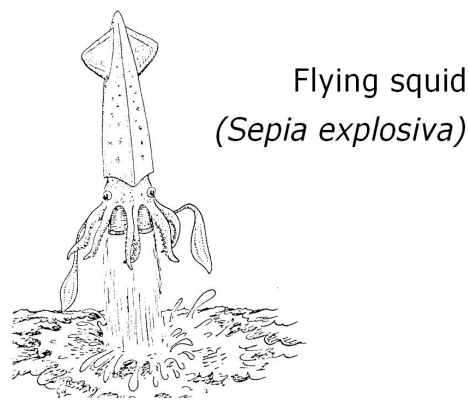

Wine thief

(Bacchus deliriosus)

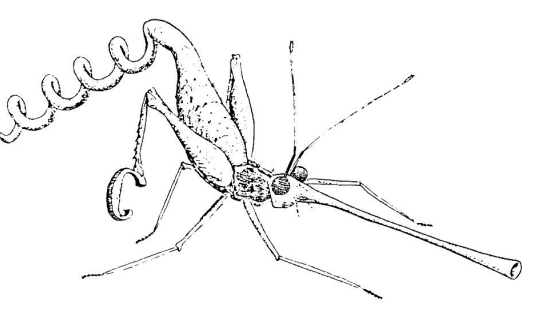

Figure 1. a-d: Vision for future life forms (courtesy Gerard 't Hooft) 


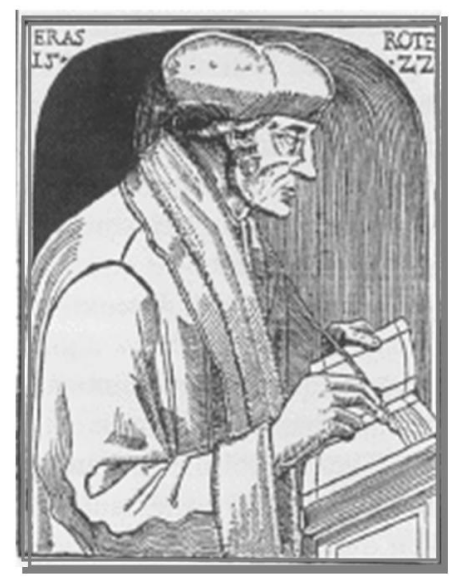

"If we want truth, every man ought to be free to say what he thinks without fear. If advocates on one side are to be rewarded with miters, and the advocates on the other with rope or stake, truth will not be heard."

- Desiderius Erasmus,

Figure 2. Portrait and quotation of humanist and philosopher Erasmus of Rotterdam

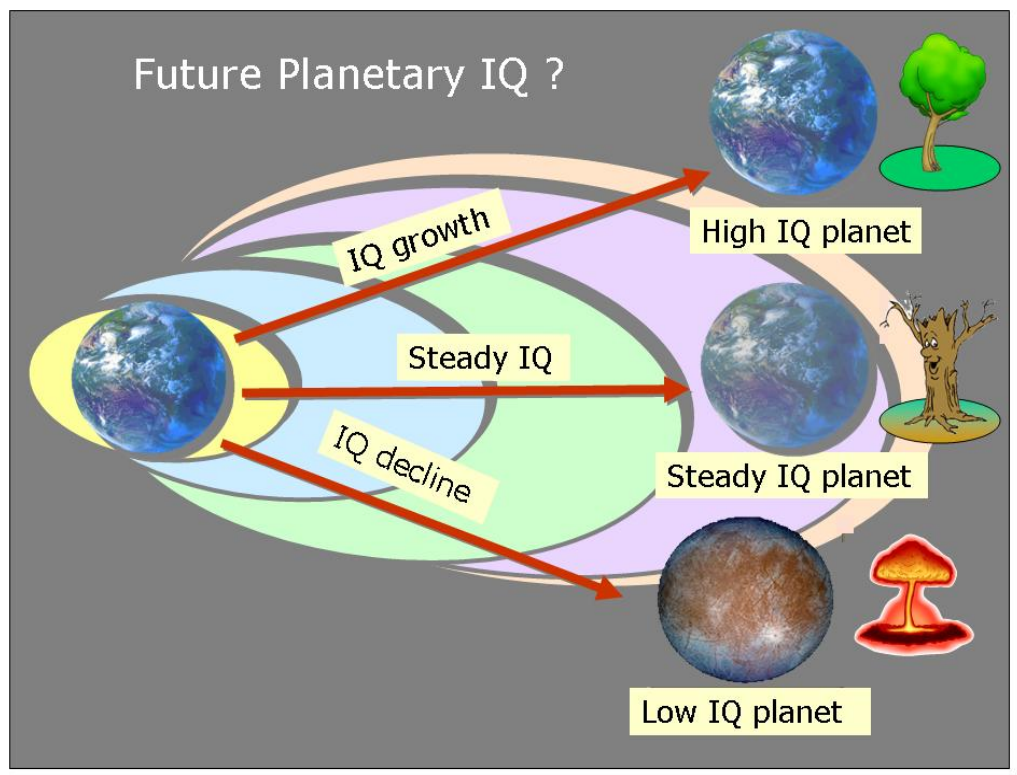

Figure 3. Vision for the future: A planet managed by its inhabitants with high Planetary IQ (Weijermars, R., 2011) is a world where inhabitants make intelligent and sustainable use of their natural resources and with respect for all species in the ecosystem. In practice, numerous threats continue to undermine the global sharing of such a vision. Plani-form ellipses are propagating timelines, non-dimensional 